\title{
Sequence spaces derived by the triple band generalized Fibonacci difference operator
}

\author{
Taja Yaying ${ }^{1}$, Bipan Hazarika², S.A. Mohiuddine ${ }^{3,4}$, M. Mursaleen ${ }^{5,6^{*}}$ (D) and Khursheed J. Ansari ${ }^{7}$
}

\author{
"Correspondence: \\ mursaleenm@gmail.com \\ ${ }^{5}$ Department of Medical Research, \\ China Medical University Hospital, \\ China Medical University (Taiwan), \\ Taichung, Taiwan \\ ${ }^{6}$ Department of Mathematics, \\ Aligarh Muslim University, Aligarh \\ 202 002, India \\ Full list of author information is \\ available at the end of the article
}

\begin{abstract}
In this article we introduce the generalized Fibonacci difference operator $F(B)$ by the composition of a Fibonacci band matrix $F$ and a triple band matrix $B(x, y, z)$ and study the spaces $\ell_{k}(F(B))$ and $\ell_{\infty}(F(B))$. We exhibit certain topological properties, construct a Schauder basis and determine the Köthe-Toeplitz duals of the new spaces. Furthermore, we characterize certain classes of matrix mappings from the spaces $\ell_{k}(F(B))$ and $\ell_{\infty}(F(B))$ to space $Y \in\left\{\ell_{\infty}, c_{0}, c, \ell_{1}, C s_{0}, C s, b s\right\}$ and obtain the necessary and sufficient condition for a matrix operator to be compact from the spaces $\ell_{k}(F(B))$ and $\ell_{\infty}(F(B))$ to $Y \in\left\{\ell_{\infty}, c, c_{0}, \ell_{1}, c s_{0}, c s, b s\right\}$ using the Hausdorff measure of non-compactness.
\end{abstract}

MSC: 46A45; 46B45; 47B07

Keywords: Fibonacci difference space; Schauder basis; $\alpha-, \beta-, \gamma$-duals; Matrix mappings; Compact operators; Hausdorff measure of non-compactness

\section{Introduction}

Throughout this paper, the set of all real valued sequences shall be denoted by $w$. Any linear subspace of $w$ is known as a sequence space. The sets $\ell_{k}$ ( $k$-absolutely summable sequences), $\ell_{\infty}$ (bounded sequences), $c_{0}$ (null sequences) and $c$ (convergent sequences) are a few examples of classical sequence spaces. Moreover, $c s$ and $b s$ will represent the spaces of all convergent and bounded series, respectively. Here and in what follows $1 \leq$ $k<\infty$, unless stated otherwise. A Banach space having continuous coordinates is known as $B K$-space. The spaces $\ell_{k}$ and $\mathrm{X}=\left\{\ell_{\infty}, c, c_{0}\right\}$ are $B K$-spaces endowed with the norms $\|s\|_{\ell_{k}}=\left(\sum_{v=0}^{\infty}\left|s_{v}\right|^{k}\right)^{1 / k}$ and $\|s\|_{\ell_{\infty}}=\sup _{v \in \mathbb{N}}\left|s_{v}\right|$, respectively.

The theory of matrix mappings plays an important role in summability theory because of its well-known property 'a matrix mapping between $B K$-spaces is continuous [6, 47]'. Let $\mathrm{X}$ and $\mathrm{Y}$ be any two sequence spaces and $\Psi=\left(\psi_{r v}\right)$ be an infinite matrix of real entries. The notation $\Psi_{r}$ shall mean the sequence in the $r$ th row of the matrix $\Psi$. Furthermore, the sequence $\Psi s=\left\{(\Psi s)_{r}\right\}=\left\{\sum_{v=0}^{\infty} \psi_{r v}\right\}$ is called the $\Psi$-transform of the sequence $s=\left(s_{r}\right) \in \mathrm{X}$, provided that the series $\sum_{v=0}^{\infty} \psi_{r v}$ exists. Furthermore, if, for each sequence $s$ in $\mathrm{X}$, its $\Psi$ transform is in $Y$, then we say that $\Psi$ is a matrix mapping from $X$ to $Y$. We shall denote the family of all matrices that map from $X$ to $Y$ by $(X: Y)$.

(c) The Author(s) 2020. This article is licensed under a Creative Commons Attribution 4.0 International License, which permits use, sharing, adaptation, distribution and reproduction in any medium or format, as long as you give appropriate credit to the original author(s) and the source, provide a link to the Creative Commons licence, and indicate if changes were made. The images or other third party material in this article are included in the article's Creative Commons licence, unless indicated otherwise in a credit line to the material. If material is not included in the article's Creative Commons licence and your intended use is not permitted by statutory regulation or exceeds the permitted use, you will need to obtain permission directly from the copyright holder. To view a copy of this licence, visit http://creativecommons.org/licenses/by/4.0/. 
Define the set

$$
\mathrm{X}_{\Psi}=\{s \in w: \Psi s \in \mathrm{X}\} .
$$

The set $X_{\Psi}$ is a sequence space and is known as the domain of matrix $\Psi$ in the space $X$. Additionally, if $\mathrm{X}$ is $B K$-space and $\Psi$ is a triangle, then $\mathrm{X}_{\Psi}$ is also $B K$-space endowed with the norm $\|s\|_{X_{\Psi}}=\|\Psi s\|_{X}[27]$, where the matrix $\Psi=\left(\psi_{r v}\right)$ is called a triangle if $\psi_{r r} \neq 0$ for all $r \in \mathbb{N}$ and $\psi_{r v}=0$ for $v>r$. Using this famous result several authors [4, 29, 35, 41, 48] in the literature constructed new $B K$-spaces. We also mention [22, 23, 26, 53-55, 62-64] for some recent publications and textbooks $[6,47,61]$ in this field.

\subsection{Difference sequence spaces}

Kizmaz [36] introduced forward difference spaces X $(\Delta)=\left\{s=\left(s_{r}\right) \in w:(\Delta s)_{r}=\left(s_{r}-s_{r+1}\right) \in\right.$ $\mathrm{X}\}$, where $\mathrm{X} \in\left\{\ell_{\infty}, c_{0}, c\right\}$. The author proved that $\mathrm{X}(\Delta)$ is a Banach space with the norm $\|s\|_{\Delta}=\left|s_{1}\right|+\|\Delta s\|_{\ell_{\infty}}$. Extending these spaces, Et [18] introduced the space $\mathrm{X}\left(\Delta^{2}\right)=\{s=$ $\left.\left(s_{r}\right) \in w:\left(\Delta^{2} s\right)_{r}=\left((\Delta s)_{r}-(\Delta s)_{r+1}\right) \in \mathrm{X}\right\}$, where $\mathrm{X} \in\left\{\ell_{\infty}, c_{0}, c\right\}$. Since then several authors $[1,12,20,21,28,38,39,42,44-46,56]$ studied and generalized the notion of difference spaces. Recently, the notion of difference spaces was further generalized by Kirişci and Başar [35] by introducing the sequence spaces $\mathrm{X}(\mathrm{B}(x, y))=(\mathrm{X})_{\mathrm{B}(x, y)}$, where $\mathrm{X} \in\left\{\ell_{\infty}, c_{0}, c\right\}$ and $\mathrm{B}(x, y)=\left\{b_{r v}(x, y)\right\}$ is the difference matrix defined by

$$
b_{r v}(x, y)= \begin{cases}x & (v=r), \\ y & (v=r-1), \\ 0 & (0 \leq v \leq r-1 \text { or } v>r),\end{cases}
$$

where $x, y \in \mathbb{R} \backslash\{0\}$.

More recently, Sönmez [57] generalized the spaces in [35] by introducing the spaces $\mathrm{X}(\mathrm{B}(x, y, z))$ for $\mathrm{X} \in\left\{\ell_{\infty}, c, c_{0}, \ell_{k}\right\}$, where $\mathrm{B}(x, y, z)=\left\{b_{r v}(x, y, z)\right\}$ is a triple band difference matrix defined by

$$
b_{r v}(x, y, z)= \begin{cases}x & (v=r) \\ y & (v=r-1) \\ z & (v=r-2) \\ 0 & \text { (otherwise) }\end{cases}
$$

where $x, y, z \in \mathbb{R} \backslash\{0\}$. Clearly $\mathrm{B}(x, y, 0)=\mathrm{B}(x, y), \mathrm{B}(1,-2,1)=\Delta^{(2)}$ and $\mathrm{B}(1,-1,0)=\Delta^{(1)}$, where $\Delta^{(1)}$ and $\Delta^{(2)}$ are the transposes of $\Delta$ and $\Delta^{2}$, respectively. We refer to $[3,5,8-$ $10,15,17,43,58,59]$ for similar studies in this domain.

\section{Fibonacci sequence spaces}

Fibonacci numbers are also considered to be Nature's numbers. They can be found everywhere around us, from the leaf arrangements in plants, to the pattern of the florets of flowers, the bracts of pinecones or the scales of pineapple. The number sequence $1,1,2,3,5,8, \ldots$ is called the Fibonacci sequence. Note that any number in the sequence 
is the sum of the two numbers preceding it. Thus, if $\left\{f_{v}\right\}_{v=0}^{\infty}$ is the sequence of Fibonacci numbers, then

$$
f_{0}=f_{1}=1 \quad \text { and } \quad f_{v}=f_{v-1}+f_{v-2}, \quad v \geq 2 .
$$

The ratio of the successive terms in the Fibonacci sequence approaches an irrational number $\frac{1+\sqrt{5}}{2}$, which is called the golden ratio. This number has great application in the field of architecture, science and arts. Some more basic properties of Fibonacci numbers [37] can be listed as follows:

$$
\begin{aligned}
& \lim _{r \rightarrow \infty} \frac{f_{r+1}}{f_{r}}=\frac{1+\sqrt{5}}{2} \quad \text { (golden ratio), } \\
& \sum_{v=0}^{r} f_{r}=f_{r+2}-1 \quad(r \in \mathbb{N}), \\
& \sum_{v=0}^{\infty} \frac{1}{f_{v}} \text { converges, } \\
& f_{r-1} f_{r+1}-f_{r}^{2}=(-1)^{r+1}, \quad r \geq 1 \text { (Cassini formula). }
\end{aligned}
$$

The Fibonacci double band matrix $\mathrm{F}=\left(f_{r v}\right)$ is defined by [29]

$$
f_{r v}= \begin{cases}-\frac{f_{r+1}}{f_{r}} & \text { if } v=r-1, \\ \frac{f_{r}}{f_{r+1}} & \text { if } v=r, \\ 0 & \text { if } 0 \leq v<r-1 \text { or } v>r .\end{cases}
$$

Kara [29] introduced the sequence spaces $\ell_{k}(\mathrm{~F})=\left(\ell_{k}\right)_{\mathrm{F}}$ and $\ell_{\infty}(\mathrm{F})=\left(\ell_{\infty}\right)_{\mathrm{F}}$. Later on, Başarır et al. [7] studied Fibonacci difference spaces $c_{0}(\mathrm{~F})=\left(c_{0}\right)_{\mathrm{F}}$ and $c(\mathrm{~F})=(c)_{\mathrm{F}}$. Since then many authors studied and generalized Fibonacci difference sequence spaces. We refer to $[11,13$, 14, 16, 30-34] for relevant studies.

Motivated by the above studies, we introduced generalized Fibonacci difference operator by the composition of the Fibonacci band matrix $F$ and the triple band matrix $\mathrm{B}(x, y, z)$. We study the domains $\ell_{k}(\mathrm{~F}(\mathrm{~B}(x, y, z)))$ and $\ell_{\infty}(\mathrm{F}(\mathrm{B}(x, y, z)))$ of the matrix operator $\mathrm{F}(\mathrm{B}(x, y, z))$ in the spaces $\ell_{k}$ and $\ell_{\infty}$, respectively, investigate certain topological properties of the spaces and construct the Schauder basis of the sequence space $\ell_{k}(\mathrm{~F}(\mathrm{~B}(x, y, z)))$. In Sect. 4, we obtain the Köthe-Toeplitz duals of the sequence spaces $\ell_{k}(\mathrm{~F}(\mathrm{~B}(x, y, z)))$. In Sect. 5, we characterize certain classes of matrix mappings from the spaces $\ell_{k}(\mathrm{~F}(\mathrm{~B}(x, y, z)))$ and $\ell_{\infty}(\mathrm{F}(\mathrm{B}(x, y, z)))$ to the space $\mathrm{Y}$, where $Y \in\left\{\ell_{\infty}, c, c_{0}, \ell_{1}, c s_{0}, c s, b s\right\}$. In Sect. 6, we characterize certain classes of compact operators on the spaces $\ell_{k}(\mathrm{~F}(\mathrm{~B}(x, y, z)))$ and $\ell_{\infty}(\mathrm{F}(\mathrm{B}(x, y, z)))$ using the Hausdorfff measure of non-compactness (or in short Hmnc).

\section{Main results}

In the present section, we introduce the product matrix $\mathrm{F}(\mathrm{B})$, where $\mathrm{B}=\mathrm{B}(x, y, z)$ is the triple band difference matrix, and obtain its inverse and introduce generalized Fibonacci difference sequence spaces $\ell_{k}(\mathrm{~F}(\mathrm{~B}))$ and $\ell_{\infty}(\mathrm{F}(\mathrm{B}))$, exhibit certain topological properties of these spaces and obtain basis of the space $\ell_{k}(\mathrm{~F}(\mathrm{~B}))$. 
Combining Fibonacci band matrix $F$ and difference operator $B$, the product matrix $F(B)=$ $(f(B))_{r v}$ is defined by

$$
(f(\mathrm{~B}))_{r v}= \begin{cases}x \frac{f_{r}}{f_{r+1}} & (r=v), \\ -x \frac{f_{\frac{1}{f}+1}}{f_{r}}+y \frac{f_{r}}{f_{r+1}} & (r=v+1), \\ -y \frac{f_{\frac{r+1}{f_{r}}}}{f_{r}}+z \frac{f_{r}}{f_{r+1}} & (r=v+2), \\ -z_{\frac{f_{r+1}}{f_{r}}} & (r=v+3), \\ 0 & \text { otherwise. }\end{cases}
$$

Equivalently, $F(B)$ can also be expressed as

$$
\mathrm{F}(\mathrm{B})=\left[\begin{array}{cccccc}
x{\frac{f}{f_{1}}}_{f_{1}} & 0 & 0 & 0 & 0 & \ldots \\
-x \frac{f_{2}}{f_{1}}+y \frac{f_{1}}{f_{2}} & x \frac{f_{1}}{f_{2}} & 0 & 0 & 0 & \ldots \\
-y \frac{f_{3}}{f_{2}}+z \frac{f_{2}}{f_{3}} & -x \frac{f_{3}}{f_{2}}+y \frac{f_{2}}{f_{3}} & x \frac{f_{2}}{f_{3}} & 0 & 0 & \ldots \\
-z \frac{f_{4}}{f_{3}} & -y \frac{f_{4}}{f_{3}}+z \frac{f_{3}}{f_{4}} & -x \frac{f_{4}}{f_{3}}+y \frac{f_{3}}{f_{4}} & x \frac{f_{3}}{f_{4}} & 0 & \ldots \\
0 & -z \frac{f_{5}}{f_{4}} & -y \frac{f_{5}}{f_{4}}+z \frac{f_{4}}{f_{5}} & -x \frac{f_{5}}{f_{4}}+y \frac{f_{4}}{f_{5}} & x f_{\frac{f}{f_{5}}} & \ldots \\
\vdots & \vdots & \vdots & \vdots & \vdots & \ddots
\end{array}\right] .
$$

One may clearly observe that $(\mathrm{F}(\mathrm{B}))(1,0,0)=\mathrm{F},(\mathrm{F}(\mathrm{B}))(x, y, 0)=(\mathrm{F}(\mathrm{B}))(x, y)$.

Now we obtain the inverse of the product matrix $F(B)$.

Lemma 3.1 ([19]) The difference operator $\mathrm{B}$ has the inverse $\mathrm{B}^{-1}=\left(b_{r v}^{-1}\right)$ defined by triangle

$$
b_{r v}^{-1}= \begin{cases}x^{-1} \sum_{j=0}^{r-v}\left(\frac{-y+\sqrt{y^{2}-4 z x}}{2 x}\right)^{r-v-j}\left(\frac{-y-\sqrt{y^{2}-4 z x}}{2 x}\right)^{j} & (0 \leq v \leq r) \\ 0 & (v>r)\end{cases}
$$

Lemma 3.2 ([7]) The Fibonacci band matrix $\mathrm{F}$ has the inverse $\mathrm{F}^{-1}$ defined by

$$
(\mathrm{F})_{r v}^{-1}= \begin{cases}\frac{f_{r+1}}{f_{v} f_{v+1}} & (0 \leq v \leq r) \\ 0 & (v>r)\end{cases}
$$

Lemma 3.3 The inverse of the product matrix $\mathrm{F}(\mathrm{B})$ is defined by the triangle

$$
(\mathrm{F}(\mathrm{B}))_{r v}^{-1}= \begin{cases}x^{-1} \sum_{i=v}^{r} \sum_{j=0}^{r-v}\left(\frac{-y+\sqrt{y^{2}-4 z x}}{2 x}\right)^{r-i-j}\left(\frac{-y-\sqrt{y^{2}-4 z x}}{2 x}\right)^{j} \frac{f_{i+1}^{2}}{f_{v v} f_{v+1}} & (0 \leq v \leq r), \\ 0 & (v>r) .\end{cases}
$$

Proof The result follows from Lemma 3.1 and Lemma 3.2.

Define the sequence $t=\left(t_{v}\right)$ in terms of the sequence $s=\left(s_{v}\right)$ by

$$
\begin{aligned}
t_{v}= & -z \frac{f_{v+1}}{f_{v}} s_{v-3}+\left(-y \frac{f_{v+1}}{f_{v}}+z \frac{f_{v}}{f_{v+1}}\right) s_{v-2}+\left(-x \frac{f_{v+1}}{f_{v}}+y \frac{f_{v}}{f_{v+1}}\right) s_{v-1} \\
& +x \frac{f_{v}}{f_{v+1}} s_{v}, \quad v \in \mathbb{N} .
\end{aligned}
$$


Note that the terms with negative subscripts is considered to be zero. The sequence $t$ is called $\mathrm{F}(\mathrm{B})$-transform of the sequence $s$.

Now we define the spaces $\ell_{k}(\mathrm{~F}(\mathrm{~B}))$ and $\ell_{\infty}(\mathrm{F}(\mathrm{B}))$ by

$$
\ell_{k}(\mathrm{~F}(\mathrm{~B}))=\left\{s=\left(s_{r}\right) \in w: \mathrm{F}(\mathrm{B}) s \in \ell_{k}\right\} \quad \text { and } \quad \ell_{\infty}(\mathrm{F}(\mathrm{B}))=\left\{s=\left(s_{r}\right) \in w: \mathrm{F}(\mathrm{B}) s \in \ell_{\infty}\right\} .
$$

The spaces $\ell_{k}(\mathrm{~F}(\mathrm{~B}))$ and $\ell_{\infty}(\mathrm{F}(\mathrm{B}))$ may be redefined in the notation of (3.2) as

$$
\ell_{k}(\mathrm{~F}(\mathrm{~B}))=\left(\ell_{k}\right)_{\mathrm{F}(\mathrm{B})} \quad \text { and } \quad \ell_{\infty}(\mathrm{F}(\mathrm{B}))=\left(\ell_{\infty}\right)_{\mathrm{F}(\mathrm{B})} .
$$

We further emphasize that the spaces $\ell_{k}(\mathrm{~F}(\mathrm{~B}))$ and $\ell_{\infty}(\mathrm{F}(\mathrm{B}))$ are reduced to certain classes of sequence spaces in the special cases of $x, y, z \in \mathbb{R}$.

1. For $x=1, y=z=0$, the above sequence spaces reduce to the classes as defined by Kara [29].

2. For $x=1, y=-1, z=0$, the above sequence spaces reduce to $\ell_{k}\left(\mathrm{~F}\left(\Delta^{(1)}\right)\right)=\left(\ell_{k}\right)_{\mathrm{F}\left(\Delta^{(1)}\right)}$ and $\ell_{\infty}\left(\mathrm{F}\left(\Delta^{(1)}\right)\right)=\left(\ell_{\infty}\right)_{\mathrm{F}\left(\Delta^{(1)}\right)}$.

3. For $x=1, y=-2, z=1$, the above sequence spaces reduce to $\ell_{k}\left(\mathrm{~F}\left(\Delta^{(2)}\right)\right)=\left(\ell_{k}\right)_{\mathrm{F}\left(\Delta^{(2)}\right)}$ and $\ell_{\infty}\left(\mathrm{F}\left(\Delta^{(2)}\right)\right)=\left(\ell_{\infty}\right)_{\mathrm{F}\left(\Delta^{(2)}\right)}$.

4. For $z=0$, the above sequence spaces reduce to the classes $\ell_{k}(\mathrm{~F}(\mathrm{~B}(x, y)))=\left(\ell_{k}\right)_{\mathrm{F}(\mathrm{B}(x, y))}$ and $\ell_{\infty}(\mathrm{F}(\mathrm{B}(x, y)))=\left(\ell_{\infty}\right)_{\mathrm{F}(\mathrm{B}(x, y))}$.

We start with the following basic theorem.

Theorem 3.4 The spaces $\ell_{k}(\mathrm{~F}(\mathrm{~B}))$ and $\ell_{\infty}(\mathrm{F}(\mathrm{B}))$ are $B K$-spaces endowed with the norms defined by

$$
\|s\|_{\ell_{k}(\mathrm{~F}(\mathrm{~B}))}=\|\mathrm{F}(\mathrm{B}) s\|_{\ell_{k}}=\left(\sum_{v=0}^{\infty}\left|(\mathrm{F}(\mathrm{B}) s)_{v}\right|^{k}\right)^{1 / k},
$$

and

$$
\|s\|_{\ell_{\infty}(\mathrm{F}(\mathrm{B}))}=\|\mathrm{F}(\mathrm{B}) s\|_{\ell_{\infty}}=\sup _{v \in \mathbb{N}}\left|(\mathrm{F}(\mathrm{B}) s)_{v}\right|
$$

respectively.

Proof The proof is a routine exercise and hence is omitted.

Theorem $3.5 \ell_{k}(\mathrm{~F}(\mathrm{~B})) \cong \ell_{k}$ and $\ell_{\infty}(\mathrm{F}(\mathrm{B})) \cong \ell_{\infty}$.

Proof We present the proof for the space $\ell_{k}(\mathrm{~F}(\mathrm{~B}))$. It is clear that the mapping $T$ : $\ell_{k}(\mathrm{~F}(\mathrm{~B})) \rightarrow \ell_{k}$ defined by $s \mapsto t=T s=\mathrm{F}(\mathrm{B}) s$ is linear and one-one. Let $t=\left(t_{r}\right) \in \ell_{k}$ define the sequence $s=\left(s_{r}\right)$ by

$$
\begin{aligned}
s_{v}= & x^{-1} \sum_{i=0}^{v} \sum_{j=i}^{v} \sum_{m=0}^{v-j}\left(\frac{-y+\sqrt{y^{2}-4 z x}}{2 x}\right)^{v-j-m}\left(\frac{-y-\sqrt{y^{2}-4 z x}}{2 x}\right)^{m} \\
& \times \frac{f_{j+1}^{2}}{f_{i} f_{i+1}} t_{i}, \quad(v \in \mathbb{N}) .
\end{aligned}
$$


Then we have

$$
\begin{aligned}
\|s\|_{\ell_{k}(\mathrm{~F}(\mathrm{~B}))=} & \|\mathrm{F}(\mathrm{B}) s\|_{\ell_{k}} \\
= & \left(\sum_{v=0}^{\infty} \mid-z \frac{f_{v+1}}{f_{v}} s_{v-3}+\left(-y \frac{f_{v+1}}{f_{v}}+z \frac{f_{v}}{f_{v+1}}\right) s_{v-2}\right. \\
& \left.+\left(-x \frac{f_{v+1}}{f_{v}}+y \frac{f_{v}}{f_{v+1}}\right) s_{v-1}+\left.x \frac{f_{v}}{f_{v+1}} s_{v}\right|^{k}\right)^{1 / k} \\
= & \left(\sum_{v=0}^{\infty}\left|t_{v}\right|^{k}\right)^{1 / k}=\|t\|_{\ell_{k}}<\infty .
\end{aligned}
$$

This implies that $s \in \ell_{k}(\mathrm{~F}(\mathrm{~B}))$. Thus we realize that $T$ is onto and norm preserving. Thus $\ell_{k}(\mathrm{~F}(\mathrm{~B})) \cong \ell_{k}$.

To end this section, we construct a sequence that forms a Schauder basis for the space $\ell_{k}(\mathrm{~F}(\mathrm{~B}))$. We recall that a Schauder basis in a normed space $\mathrm{X}$ is a sequence $s=\left(s_{r}\right)$ such that to every element $u$ in $\mathrm{X}$ there corresponds a unique sequence of scalars $\left(a_{r}\right)$ satisfying

$$
\lim _{r \rightarrow \infty}\left\|u-\sum_{v=0}^{r} a_{v} s_{v}\right\|=0
$$

Let $e^{(v)}$ denote the sequence with 1 in the $v$ th position and 0 elsewhere. We are well aware that the set $\left\{e^{(v)}: v \in \mathbb{N}\right\}$ is a Schauder basis of the space $\ell_{k}$. Moreover, the mapping $T$ defined in Theorem 3.5 is onto, therefore the inverse image of the set $\left\{e^{(v)}\right\}$ forms the basis of the space $\ell_{k}(\mathrm{~F}(\mathrm{~B}))$. This statement gives us the following result.

Theorem 3.6 Define the sequence $c^{(v)}=\left(c_{r}^{(v)}\right)$ for every fixed $v \in \mathbb{N}$ by

$$
c_{r}^{(v)}= \begin{cases}x^{-1} \sum_{j=\nu}^{r} \sum_{m=0}^{r-j}\left(\frac{-y+\sqrt{y^{2}-4 z x}}{2 x}\right)^{r-j-m}\left(\frac{-y-\sqrt{y^{2}-4 z x}}{2 x}\right)^{m} \frac{f_{j+1}^{2}}{f_{v f_{v+1}}} & (0 \leq v \leq r), \\ 0 & (v>r),\end{cases}
$$

for each $r \in \mathbb{N}$. Then the sequence $\left(c^{(v)}\right)$ is a Schauder basis for the space $\ell_{k}(\mathrm{~F}(\mathrm{~B}))$ and every $s \in \ell_{k}(\mathrm{~F}(\mathrm{~B}))$ can be uniquely expressed in the form $s=\sum_{v=0}^{r} \lambda_{v} c^{(v)}$, where $\lambda_{v}=(\mathrm{F}(\mathrm{B}) s)_{v}$ for each $v \in \mathbb{N}$.

Corollary 3.7 The sequence space $\ell_{k}(\mathrm{~F}(\mathrm{~B}))$ is separable.

Proof The result follows from Theorems 3.4 and 3.6.

\section{Köthe-Toeplitz duals (or $\alpha$-, $\beta$ - and $\gamma$-duals)}

In present section, we determine Köthe-Toeplitz duals of the space $\ell_{k}(\mathrm{~F}(\mathrm{~B}))$ and $\ell_{\infty}(\mathrm{F}(\mathrm{B}))$. It is to mention that we have not provided the proof for the case $k=1$ as the proof is similar to the case $1<k \leq \infty$. The proofs are provided only for the latter case.

The $\alpha$-, $\beta$ - and $\gamma$-duals of the space $\mathrm{X} \subset w$ are defined by

$$
[\mathrm{X}]^{\alpha}=\left\{\varsigma=\left(\varsigma_{r}\right) \in w: \varsigma s=\left(\varsigma_{r} s_{r}\right) \in \ell_{1}, \forall s=\left(s_{r}\right) \in \mathrm{X}\right\},
$$




$$
\begin{aligned}
& {[X]^{\beta}=\left\{\varsigma=\left(\varsigma_{r}\right) \in w: \varsigma s=\left(\varsigma_{r} s_{r}\right) \in c s, \forall s=\left(s_{r}\right) \in \mathrm{X}\right\},} \\
& {[X]^{\gamma}=\left\{\varsigma=\left(\varsigma_{r}\right) \in w: \varsigma s=\left(\varsigma_{r} s_{r}\right) \in b s, \forall s=\left(s_{r}\right) \in \mathrm{X}\right\},}
\end{aligned}
$$

respectively.

Before proceeding further, we list celebrated results of Stielglitz and Tietz [60] that are essential for our investigation. In the rest of the paper, $\frac{1}{k}+\frac{1}{k^{\prime}}=1$ and $\mathcal{R}$ is the family of all finite subsets of $\mathbb{N}$.

Lemma 4.1 $\Psi=\left(\psi_{r v}\right) \in\left(\ell_{k}: \ell_{1}\right)$ if and only if

$$
\sup _{R \in \mathcal{R}} \sum_{v=0}^{\infty}\left|\sum_{r \in R} \psi_{r v}\right|<\infty, \quad 1<k \leq \infty
$$

Lemma 4.2 $\Psi=\left(\psi_{r v}\right) \in\left(\ell_{k}: c\right)$ if and only if

$$
\begin{aligned}
& \lim _{r \rightarrow \infty} \psi_{r v} \text { exists } \text { for all } v \in \mathbb{N}, \\
& \sup _{r \in \mathbb{N}} \sum_{v=0}^{\infty}\left|\psi_{r v}\right|^{k^{\prime}}<\infty, \quad 1<k<\infty .
\end{aligned}
$$

Lemma 4.3 $\Psi=\left(\psi_{r v}\right) \in\left(\ell_{\infty}: c\right)$ if and only if (4.1) holds and

$$
\lim _{r \rightarrow \infty} \sum_{v=0}^{r}\left|\psi_{r v}\right|=\sum_{v=0}^{\infty}\left|\lim _{r \rightarrow \infty} \psi_{r v}\right| .
$$

Lemma 4.4 $\Psi=\left(\psi_{r v}\right) \in\left(\ell_{k}: \ell_{\infty}\right)$ if and only if (4.2) holds with $1<k \leq \infty$.

Theorem 4.5 Define the sets $\delta^{\left(k^{\prime}\right)}$ and $\delta_{\infty}$ by

$$
\begin{aligned}
\delta^{\left(k^{\prime}\right)} & =\left\{\varsigma=\left(\zeta_{r}\right) \in w: \sup _{R \in \mathcal{R}} \sum_{v=0}^{\infty}\left|\sum_{r \in R} d_{r v}\right|^{k^{\prime}}<\infty\right\}, \\
\delta_{\infty} & =\left\{\varsigma=\left(\zeta_{r}\right) \in w: \sup _{v \in \mathbb{N}} \sum_{r=0}^{\infty}\left|d_{r v}\right|<\infty\right\},
\end{aligned}
$$

where the matrix $D=\left(d_{r v}\right)$ is defined by

$$
d_{r v}= \begin{cases}x^{-1} \sum_{j=v}^{r} \sum_{m=0}^{r-j}\left(\frac{-y+\sqrt{y^{2}-4 z x}}{2 x}\right)^{r-j-m}\left(\frac{-y-\sqrt{y^{2}-4 z x}}{2 x}\right)^{m} \frac{f_{j+1}^{2}}{f_{v} f_{v+1}} \varsigma_{r} & (0 \leq v \leq r), \\ 0 & (v>r),\end{cases}
$$

for all $r, v \in \mathbb{N}$. Then $\left[\ell_{1}(\mathrm{~F}(\mathrm{~B}))\right]^{\alpha}=\delta_{\infty},\left[\ell_{k}(\mathrm{~F}(\mathrm{~B}))\right]^{\alpha}=\delta^{\left(k^{\prime}\right)}$ and $\left[\ell_{\infty}(\mathrm{F}(\mathrm{B}))\right]^{\alpha}=\delta^{(1)}$.

Proof Let $1<k \leq \infty$. Let $\varsigma=\left(\varsigma_{r}\right) \in w$ and $s=\left(s_{r}\right)$ be defined in (3.6), then we have

$$
\begin{aligned}
\varsigma_{r} s_{r} & =x^{-1} \sum_{i=0}^{r} \sum_{j=i}^{r} \sum_{m=0}^{r-j}\left(\frac{-y+\sqrt{y^{2}-4 z x}}{2 x}\right)^{r-j-m}\left(\frac{-y-\sqrt{y^{2}-4 z x}}{2 x}\right)^{m} \frac{f_{j+1}^{2}}{f_{i} f_{i+1}} \varsigma_{r} t_{i} \\
& =(D t)_{r}, \quad \text { for each } r \in \mathbb{N} .
\end{aligned}
$$


Thus we deduce from (4.4) that $\varsigma s=\left(\varsigma_{r} s_{r}\right) \in \ell_{1}$ whenever $s=\left(s_{r}\right) \in \ell_{k}(\mathrm{~F}(\mathrm{~B}))$ if only if $D t \in$ $\ell_{1}$ whenever $t=\left(t_{r}\right) \in \ell_{k}$, which implies that $\varsigma=\left(\varsigma_{r}\right) \in\left[\ell_{k}(\mathrm{~F}(\mathrm{~B}))\right]^{\alpha}$ if and only if $D \in\left(\ell_{k}: \ell_{1}\right)$.

Thus by using Lemma 4.1, we conclude that

$$
\left[\ell_{k}(\mathrm{~F}(\mathrm{~B}))\right]^{\alpha}=\delta^{\left(k^{\prime}\right)} \text { and }\left[\ell_{\infty}(\mathrm{F}(\mathrm{B}))\right]^{\alpha}=\delta^{(1)}
$$

Theorem 4.6 Define the sets $\delta_{1}, \delta_{2}$ and $\delta_{3}$ by

$$
\begin{aligned}
& \delta_{1}=\left\{\varsigma=\left(\zeta_{r}\right) \in w: \lim _{r \rightarrow \infty} g_{r v} \text { exists for all } v \in \mathbb{N}\right\} ; \\
& \delta_{2}=\left\{\varsigma=\left(\zeta_{r}\right) \in w: \sup _{r, v \in \mathbb{N}}\left|g_{r v}\right|<\infty\right\} ; \\
& \delta_{3}=\left\{\varsigma=\left(\zeta_{r}\right) \in w: \lim _{r \rightarrow \infty} \sum_{v=0}^{r}\left|g_{r v}\right|=\sum_{v=0}^{\infty}\left|\lim _{r \rightarrow \infty} g_{r v}\right|<\infty\right\} ; \\
& \delta^{\left[k^{\prime}\right]}=\left\{\varsigma=\left(\zeta_{r}\right) \in w: \sup _{r \in \mathbb{N}} \sum_{v=0}^{r}\left|g_{r v}\right|^{k^{\prime}}<\infty\right\} ;
\end{aligned}
$$

where the matrix $G=\left(g_{r v}\right)$ is defined by

$$
g_{r v}= \begin{cases}\sum_{i=v}^{r} \sum_{j=v}^{i} \sum_{m=0}^{i-j}\left(\frac{-y+\sqrt{y^{2}-4 z x}}{2 x}\right)^{i-j-m}\left(\frac{-y-\sqrt{y^{2}-4 z x}}{2 x}\right)^{m} \frac{f_{j+1}^{2}}{f_{v} f_{v+1}} \varsigma_{r} & (0 \leq v \leq r), \\ 0 & (v>r) .\end{cases}
$$

Then $\left[\ell_{1}(\mathrm{~F}(\mathrm{~B}))\right]^{\beta}=\delta_{1} \cap \delta_{2},\left[\ell_{k}(\mathrm{~F}(\mathrm{~B}))\right]^{\beta}=\delta_{1} \cap \delta^{\left[k^{\prime}\right]}$ and $\left[\ell_{\infty}(\mathrm{F}(\mathrm{B}))\right]^{\beta}=\delta_{1} \cap \delta_{3}$.

Proof Let $\varsigma=\left(\varsigma_{r}\right) \in w$ and $s=\left(s_{r}\right)$ be defined in (3.6). Consider the equality

$$
\begin{aligned}
\sum_{v=0}^{r} \varsigma_{v} s_{v} & =\sum_{v=0}^{r} \varsigma_{v}\left[x^{-1} \sum_{i=0}^{v} \sum_{j=i}^{v} \sum_{m=0}^{v-j}\left(\frac{-y+\sqrt{y^{2}-4 z x}}{2 x}\right)^{v-j-m}\left(\frac{-y-\sqrt{y^{2}-4 z x}}{2 x}\right)^{m} \frac{f_{j+1}^{2}}{f_{i} f_{i+1}} t_{i}\right] \\
& =\sum_{v=0}^{r}\left[x^{-1} \sum_{i=v}^{r} \sum_{j=v}^{i} \sum_{m=0}^{i-j}\left(\frac{-y+\sqrt{y^{2}-4 z x}}{2 x}\right)^{i-j-m}\left(\frac{-y-\sqrt{y^{2}-4 z x}}{2 x}\right)^{m} \frac{f_{j+1}^{2}}{f_{v} f_{v+1}} \varsigma_{i}\right] t_{v} \\
& =(E t)_{r}, \quad \text { for each } r \in \mathbb{N} .
\end{aligned}
$$

Thus $\varsigma s=\left(\varsigma_{v} s_{v}\right) \in c s$ whenever $s=\left(s_{r}\right) \in \ell_{k}(\mathrm{~F}(\mathrm{~B}))$ if only if $E t \in c$ whenever $t=\left(t_{v}\right) \in \ell_{k}$. Thus $\varsigma=\left(\varsigma_{v}\right) \in\left[\ell_{k}(\mathrm{~F}(\mathrm{~B}))\right]^{\beta}$ if and only if $E \in\left(\ell_{k}: c\right)$.

Thus we conclude from Lemma 4.2 that $\left[\ell_{k}(\mathrm{~F}(\mathrm{~B}))\right]^{\beta}=\delta_{1} \cap \delta^{\left[k^{\prime}\right]}$.

Similar proof can be written for the case $p=\infty$ by replacing Lemma 4.2 with Lemma 4.3.

Theorem $4.7\left[\ell_{1}(\mathrm{~F}(\mathrm{~B}))\right]^{\gamma}=\delta_{2},\left[\ell_{k}(\mathrm{~F}(\mathrm{~B}))\right]^{\gamma}=\delta^{\left[k^{\prime}\right]}$ and $\left[\ell_{\infty}(\mathrm{F}(\mathrm{B}))\right]^{\gamma}=\delta^{[1]}$.

Proof The proof is analogous to the proof of previous theorem except that Lemma 4.4 is employed instead of Lemma 4.2. 


\section{Matrix mappings}

In the present section, we characterize certain class of matrix mappings from the spaces $\ell_{k}(\mathrm{~F}(\mathrm{~B}))$ and $\ell_{\infty}(\mathrm{F}(\mathrm{B}))$ to the space $\mathrm{Y} \in\left\{\ell_{\infty}, c, c_{0}, \ell_{1}, b s, c s, c s_{0}\right\}$. The following theorem is fundamental in our investigation.

Theorem 5.1 Let $1 \leq k \leq \infty$ and $X$ be any arbitrary subset of $w$. Then $\Psi=\left(\psi_{r v}\right) \in$ $\left(\ell_{k}(\mathrm{~F}(\mathrm{~B})): \mathrm{X}\right)$ if and only if $\Phi^{(r)}=\left(\phi_{m v}^{(r)}\right) \in\left(\ell_{k}: c\right)$ for each $r \in \mathbb{N}$, and $\Phi=\left(\psi_{r v}\right) \in\left(\ell_{k}: \mathrm{X}\right)$, where

$$
\phi_{m v}^{(r)}= \begin{cases}0 & (v>m), \\ \sum_{j=v}^{m} x^{-1} \sum_{l=0}^{r-j}\left(\frac{-y+\sqrt{y^{2}-4 z x}}{2 x}\right)^{r-j-l}\left(\frac{-y-\sqrt{y^{2}-4 z x}}{2 x}\right)^{l} \frac{f_{j+1}^{2}}{f_{v} f_{v+1}} \psi_{r j} & (0 \leq v \leq m),\end{cases}
$$

and

$$
\phi_{r v}=\sum_{j=v}^{\infty} x^{-1} \sum_{l=0}^{r-j}\left(\frac{-y+\sqrt{y^{2}-4 z x}}{2 x}\right)^{r-j-l}\left(\frac{-y-\sqrt{y^{2}-4 z x}}{2 x}\right)^{l} \frac{f_{j+1}^{2}}{f_{v} f_{v+1}} \psi_{r j}
$$

for all $r, v \in \mathbb{N}$.

Proof The result immediately follows from the proof of Theorem 4.1 of [35]. Hence we omit the details.

Now, using the results presented in Stielglitz and Tietz [60] together with Theorem 5.1, we obtain the following results.

Corollary 5.2 The following statements hold:

1. $\Psi \in\left(\ell_{1}(\mathrm{~F}(\mathrm{~B})): \ell_{\infty}\right)$ if and only if

$$
\begin{aligned}
& \lim _{m \rightarrow \infty} \phi_{m \nu}^{(r)} \text { exists for all } r, v \in \mathbb{N}, \\
& \sup _{r, v \in \mathbb{N}}\left|\phi_{m \nu}^{(r)}\right|<\infty, \\
& \sup _{r, v \in \mathbb{N}}\left|\phi_{r v}\right|<\infty,
\end{aligned}
$$

2. $\Psi \in\left(\ell_{1}(\mathrm{~F}(\mathrm{~B})): c\right)$ if and only if (5.2) and (5.3) hold, and (5.4) and

$$
\lim _{r \rightarrow \infty} \phi_{r v} \text { exists for all } v \in \mathbb{N},
$$

also hold.

3. $\Psi \in\left(\ell_{1}(\mathrm{~F}(\mathrm{~B})): c_{0}\right)$ if and only if (5.2) and (5.3) hold, and (5.4) and

$$
\lim _{r \rightarrow \infty} \phi_{r v}=0 \quad \text { for all } v \in \mathbb{N}
$$

also hold.

4. $\Psi \in\left(\ell_{1}(\mathrm{~F}(\mathrm{~B})): \ell_{1}\right)$ if and only if (5.2) and (5.3) hold, and

$$
\sup _{v \in \mathbb{N}} \sum_{r=0}^{\infty}\left|\phi_{r v}\right|<\infty
$$

also holds. 
5. $\Psi \in\left(\ell_{1}(\mathrm{~F}(\mathrm{~B})):\right.$ bs) if and only if (5.2) and (5.3) hold, and (5.4) also holds with $\Phi(r, v)$ instead of $\phi_{r v}$, where $\Phi(r, v)=\sum_{l=0}^{r} \phi_{l v}$.

6. $\Psi \in\left(\ell_{1}(\mathrm{~F}(\mathrm{~B})):\right.$ cs) if and only if (5.2) and (5.3) hold, and (5.4) and (5.5) also hold with $\Phi(r, v)$ instead of $\phi_{r v}$, where $\Phi(r, v)=\sum_{l=0}^{r} \phi_{l v}$.

7. $\Phi \in\left(\ell_{1}(\mathrm{~F}(\mathrm{~B})): c s_{0}\right)$ if and only if (5.2) and (5.3) hold, and (5.4) and (5.6) also hold with $\Phi(r, v)$ instead of $\phi_{r v}$, where $\Phi(r, v)=\sum_{l=0}^{r} \phi_{l v}$.

Corollary 5.3 The following statements hold:

1. $\Psi \in\left(\ell_{k}(\mathrm{~F}(\mathrm{~B})): \ell_{\infty}\right)$ if and only if (5.2) holds, and

$$
\begin{aligned}
& \sup _{m \in \mathbb{N}} \sum_{v=0}^{m}\left|\phi_{m v}^{(r)}\right|^{k^{\prime}}<\infty, \\
& \sup _{r \in \mathbb{N}} \sum_{v=0}^{r}\left|\phi_{r v}\right|^{k^{\prime}}<\infty,
\end{aligned}
$$

also hold.

2. $\Psi \in\left(\ell_{k}(\mathrm{~F}(\mathrm{~B})): c\right)$ if and only if (5.2) and (5.8) hold, and (5.5) and (5.9) also hold.

3. $\Psi \in\left(\ell_{k}(\mathrm{~F}(\mathrm{~B})): c_{0}\right)$ if and only if (5.2) and (5.8) hold, (5.6) and (5.9) also hold.

4. $\Psi \in\left(\ell_{k}(\mathrm{~F}(\mathrm{~B})): \ell_{1}\right)$ if and only if (5.2) and (5.8) hold, and

$$
\sup _{R \in \mathcal{R}} \sum_{v=0}^{\infty}\left|\sum_{r \in R} \phi_{r v}\right|^{k^{\prime}}<\infty
$$

also holds.

5. $\Psi \in\left(\ell_{k}(\mathrm{~F}(\mathrm{~B})):\right.$ ss) if and only if (5.2) and (5.8) hold, and (5.9) also holds with $\Phi(r, v)$ instead of $\phi_{r v}$, where $\Phi(r, v)=\sum_{l=0}^{r} \phi_{l v}$.

6. $\Psi \in\left(\ell_{k}(\mathrm{~F}(\mathrm{~B})): c s\right)$ if and only if (5.2) and (5.8) hold, and (5.5) and (5.9) also hold.

7. $\Psi \in\left(\ell_{k}(\mathrm{~F}(\mathrm{~B})): c s_{0}\right)$ if and only if (5.2) and (5.8) hold, and (5.6) and (5.9) also hold with $\Phi(r, v)$ instead of $\phi_{r v}$, where $\Phi(r, v)=\sum_{l=0}^{r} \phi_{l v}$.

\section{Corollary 5.4 The following statements hold:}

1. $\Psi \in\left(\ell_{\infty}(\mathrm{F}(\mathrm{B})): \ell_{\infty}\right)$ if and only if $(5.2)$ and

$$
\lim _{m \rightarrow \infty} \sum_{v=0}^{m}\left|\phi_{m v}^{(r)}\right|=\sum_{v=0}^{m}\left|\lim _{m \rightarrow \infty} \phi_{m v}^{(r)}\right| \quad \text { for each } r \in \mathbb{N}
$$

hold, and (5.9) also holds with $k^{\prime}=1$.

2. $\Psi \in\left(\ell_{\infty}(\mathrm{F}(\mathrm{B})): c\right)$ if and only if (5.2) and (5.11) hold, and (5.5) and

$$
\lim _{r \rightarrow \infty} \sum_{v=0}^{r}\left|\phi_{r v}\right|=\sum_{v=0}^{r}\left|\lim _{r \rightarrow \infty} \phi_{r v}\right|
$$

also hold.

3. $\Psi \in\left(\ell_{\infty}(\mathrm{F}(\mathrm{B})): c_{0}\right)$ if and only if (5.2) and (5.11) hold, and

$$
\lim _{r \rightarrow \infty} \sum_{v=0}^{r} \phi_{r v}=0
$$

also holds. 
4. $\Psi \in\left(\ell_{\infty}(\mathrm{F}(\mathrm{B})): \ell_{1}\right)$ if and only if (5.2) and (5.11) hold, and (5.10) also holds with $k^{\prime}=1$.

5. $\Psi \in\left(\ell_{\infty}(\mathrm{F}(\mathrm{B}))\right.$ : bs) if and only if (5.2) and (5.11) hold, and (5.9) also hold with $k^{\prime}=1$, and $\Phi(r, v)$ instead of $\phi_{r v}$, where $\Phi(r, v)=\sum_{l=0}^{r} \phi_{l v}$.

6. $\Psi \in\left(\ell_{\infty}(\mathrm{F}(\mathrm{B})): c s\right)$ if and only if (5.2) and (5.11) hold, and (5.12) also holds with $\Phi(r, v)$ instead of $\phi_{r v}$, where $\Phi(r, v)=\sum_{l=0}^{r} \phi_{l v}$.

7. $\Psi \in\left(\ell_{\infty}(\mathrm{F}(\mathrm{B})): c s_{0}\right)$ if and only if (5.2) and (5.11) hold, and (5.13) also holds with $\Phi(r, v)$ instead of $\phi_{r v}$, where $\Phi(r, v)=\sum_{l=0}^{r} \phi_{l v}$.

\section{Hausdorff measure of non-compactness (Hmnc)}

In the current section, $B(\mathrm{X})$ shall denote the unit ball in $\mathrm{X}$. The notation $B(\mathrm{X}: \mathrm{Y})$ represents the family of all bounded linear operators acting from Banach spaces $X$ to $Y$, which itself is a Banach space endowed with the operator norm $\|C\|=\sup _{s \in B(\mathrm{X})}\|C s\|$. We denote

$$
\|\varsigma\|_{\mathrm{X}}^{*}=\sup _{s \in B(\mathrm{X})}\left|\sum_{v=0}^{\infty} \varsigma_{v} s_{v}\right|
$$

for $\varsigma \in w$, provided that the series on the right hand side of (6.1) exists. One may clearly observe that $\varsigma \in X^{\beta}$. Furthermore, the operator $C$ is said to be compact if the domain of $X$ is all of $\mathrm{X}$ and for every bounded sequence $\left(s_{r}\right)$ in $\mathrm{X}$, the sequence $\left((C s)_{r}\right)$ has a convergent subsequence in $\mathrm{Y}$.

The Hmnc of a bounded set $J$ in a metric space $\mathrm{X}$ is defined by

$$
\chi(J)=\inf \left\{\varepsilon>0: J \subset \bigcup_{l=0}^{r} B\left(s_{l}, n_{l}\right), s_{l} \in \mathrm{X}, n_{l}<\varepsilon(l=0,1,2, \ldots, r), r \in \mathbb{N}\right\},
$$

where $B\left(s_{l}, n_{l}\right)$ represents unit ball with centre $s_{l}$ and radius $n_{l}$ and $l=0,1,2, \ldots, r$.

$H m n c$ is an important tool that determines the compactness of an operator between $B K$ spaces. An operator $C: X \rightarrow Y$ is compact if and only if $\|C\|_{\chi}=0$, where $\|C\|_{\chi}$ represents Hmnc of the operator $\mathrm{C}$ and is defined by $\|C\|_{\chi}=\chi(C(B(\mathrm{X})))$. Using Hmnc, several authors obtained necessary and sufficient conditions for matrix operators to be compact between well-known $B K$-spaces. For relevant literature, one may refer to [2, 13, 40, 49-52]. The reader may also consult the recent publications [22, 24, 25, 53, 62], which are related to compact operators and Hmnc in $B K$-spaces.

Before proceeding to the main results of this section, we list certain well-known results that are crucial in finding our result below.

Lemma 6.1 $\ell_{1}^{\beta}=\ell_{\infty}, \ell_{k}^{\beta}=\ell_{k^{\prime}}$ and $\ell_{\infty}^{\beta}=\ell_{1}$. Furthermore, if $\mathrm{X} \in\left\{\ell_{1}, \ell_{k}, \ell_{\infty}\right\}$, then $\|\varsigma\|_{\mathrm{X}}^{*}=$ $\|\varsigma\|_{X^{\beta}}$ holds for all $\varsigma \in \mathrm{X}^{\beta}$, where $\|\cdot\|_{X^{\beta}}$ is the natural norm on $\mathrm{X}^{\beta}$.

Lemma 6.2 ([61, Theorem 4.2.8]) Let $\mathrm{X}$ and $\mathrm{Y}$ be two BK-spaces. Then we have $(\mathrm{X}: \mathrm{Y}) \subset$ $B(\mathrm{X}: \mathrm{Y})$, that is, every $\Psi \in(\mathrm{X}: \mathrm{Y})$ defines a linear operator $C_{\Psi} \in B(\mathrm{X}: \mathrm{Y})$, where $\mathrm{C}_{\Psi} s=\Psi$ s for all $s \in \mathrm{X}$.

Lemma 6.3 ([40, Theorem 1.23]) Let $\mathrm{X} \supset \vartheta$ be a BK space. If $\Psi \in(\mathrm{X}: \mathrm{Y})$ then

$$
\left\|C_{\Psi}\right\|=\|\Psi\|_{(\mathrm{X}: Y)}=\sup _{r \in \mathbb{N}}\left\|\Psi_{r}\right\|_{\mathrm{X}}^{*}<\infty
$$


Lemma 6.4 ([40, Theorem 2.15]) Let $J$ be a bounded subset of $\ell_{k}$. If $P_{r}: \ell_{k} \rightarrow \ell_{k}$ is the operator defined by $P_{r}\left(s_{0}, s_{1}, s_{2}, \ldots\right)=\left(s_{0}, s_{1}, s_{2}, \ldots, s_{r}, 0,0, \ldots\right)$ for all $s=\left(s_{r}\right) \in \mathrm{X}$, then

$$
\chi(Q)=\lim _{r \rightarrow \infty}\left(\sup _{s \in J}\left\|\left(I_{\mathrm{X}}-P_{r}\right) s\right\|\right)
$$

where $I_{\mathrm{X}}$ is the identity operator on $\mathrm{X}$.

Lemma 6.5 ([50, Theorem 3.7]) Let X $\supset \vartheta$ be a BK-space. Then the following statements hold:

(a) If $\Psi \in\left(\mathrm{X}: c_{0}\right)$, then $\left\|C_{\Psi}\right\|_{\chi}=\lim \sup _{r \rightarrow \infty}\left\|\Psi_{r}\right\|_{\mathrm{X}}^{*}$ and $\mathrm{C}_{\Psi}$ is compact if and only if $\lim _{r \rightarrow \infty}\left\|\Psi_{r}\right\|_{\mathrm{X}}^{*}=0$.

(b) If $\mathrm{X}$ has $A K$ and $\Psi \in(\mathrm{X}: c)$, then

$$
\frac{1}{2} \limsup _{r \rightarrow \infty}\left\|\Psi_{r}-\alpha\right\|_{x}^{*} \leq\left\|C_{\Psi}\right\|_{\chi} \leq \limsup _{r \rightarrow \infty}\left\|\Psi_{r}-\alpha\right\|_{\chi}^{*}
$$

and $\mathrm{C}_{\Psi}$ is compact if and only if $\lim _{r \rightarrow \infty}\left\|\Psi_{r}-\alpha\right\|_{\mathrm{X}}^{*}=0$, where $\alpha=\left(\alpha_{\nu}\right)$ with $\alpha_{v}=\lim _{r \rightarrow \infty} \psi_{r v}$ for all $v \in \mathbb{N}$.

(c) If $\Psi \in\left(\mathrm{X}: \ell_{\infty}\right)$, then $0 \leq\left\|C_{\Psi}\right\|_{X} \leq \lim \sup _{r \rightarrow \infty}\left\|\Psi_{r}\right\|_{\mathrm{X}}^{*}$ and $\mathrm{C}_{\Psi}$ is compact if and only if $\lim _{r \rightarrow \infty}\left\|\Psi_{r}\right\|_{\mathrm{X}}^{*}=0$.

Lemma 6.6 ([50, Theorem 3.11]) Let $\mathrm{X} \supset \vartheta$ be a $B K$-space. If $\Psi \in\left(\mathrm{X}: \ell_{1}\right)$, then

$$
\lim _{m \rightarrow \infty}\left(\sup _{R \in \mathcal{R}_{m}}\left\|\sum_{r \in R} \Psi_{r}\right\|_{X}^{*}\right) \leq\left\|C_{\Psi}\right\|_{\chi} \leq 4 \cdot \lim _{m \rightarrow \infty}\left(\sup _{R \in \mathcal{R}_{m}}\left\|\sum_{r \in R} \Psi_{r}\right\|_{X}^{*}\right)
$$

and $C_{\Psi}$ is compact if and only if $\lim _{m \rightarrow \infty}\left(\sup _{R \in \mathcal{R}_{m}}\left\|\sum_{r \in R} \Psi_{r}\right\|_{\mathrm{X}}^{*}\right)=0$, where $\mathcal{R}_{m}$ is the subfamily of $\mathcal{R}$ consisting of subsets of $\mathbb{N}$ with elements that are greater than $m$.

Lemma 6.7 ([50, Theorem 4.4, Corollary 4.5]) Let X $\supset \vartheta$ be a BK-space and let

$$
\|\Psi\|_{b s}^{[r]}=\left\|\sum_{\nu=0}^{r} \Psi_{v}\right\|_{\mathrm{X}}^{*} .
$$

Then we have the following results:

(a) If $\Psi \in\left(\mathrm{X}: c s_{0}\right)$, then $\left\|C_{\Psi}\right\|_{\chi}=\lim \sup _{r \rightarrow \infty}\|\Psi\|_{(\mathrm{X}: b s)}^{[r]}$ and $C_{\Psi}$ is compact if and only if $\lim _{r \rightarrow \infty}\|\Psi\|_{(\mathrm{X}: b s)}^{[r]}=0$.

(b) If $\mathrm{X}$ has $A K$ and $\Psi \in(\mathrm{X}: c s)$, then

$$
\frac{1}{2} \limsup _{r \rightarrow \infty}\left\|\sum_{\nu=0}^{r} \Psi_{\nu}-\beta\right\|_{\mathrm{X}}^{*} \leq\left\|C_{\Psi}\right\|_{\chi} \leq \limsup _{r \rightarrow \infty}\left\|\sum_{\nu=0}^{r} \Psi_{r}-\beta\right\|_{\mathrm{X}}^{*}
$$

Furthermore, $C_{\Psi}$ is compact if and only if $\lim _{r \rightarrow \infty}\left\|\sum_{v=0}^{r} \Psi_{r}-\beta\right\|_{\mathrm{X}}^{*}=0$, where $\beta=\left(\beta_{v}\right)$ with $\beta_{v}=\lim _{r \rightarrow \infty} \sum_{l=0}^{r} \psi_{l v}$ for all $v \in \mathbb{N}_{0}$.

(c) If $\Psi \in(\mathrm{X}: b s)$, then $0 \leq\left\|C_{\Psi}\right\|_{\chi} \leq \lim \sup _{r \rightarrow \infty}\|\Psi\|_{(\mathrm{X}: b s)}^{[r]}$ and $C_{\Psi}$ is compact if and only if $\lim _{r \rightarrow \infty}\|\Psi\|_{(\mathrm{X}: b s)}^{[r]}=0$. 
Lemma 6.8 Let $\mathrm{X}$ be a sequence space and $\Psi=\left(\psi_{r v}\right)$ be an infinite matrix. If $\Psi \in\left(\ell_{k}(\mathrm{~F}(\mathrm{~B}))\right.$ : $\mathrm{X})$, then $\Phi \in\left(\ell_{k}: \mathrm{X}\right)$ and $\Psi s=\Phi$ t for all $s \in \ell_{k}(\mathrm{~F}(\mathrm{~B})), 1 \leq k \leq \infty$, where $\Phi=\left(\phi_{r v}\right)$ is as defined in (5.1) and the sequence $t$ is a $\mathrm{F}(\mathrm{B})$-transform of the sequence $s$.

Proof Let $\Psi \in\left(\ell_{k}(\mathrm{~F}(\mathrm{~B})): \mathrm{X}\right)$ and $s \in \ell_{k}(\mathrm{~F}(\mathrm{~B}))$. Then $\Psi_{r}=\left(\psi_{r v}\right)_{v \in \mathbb{N}} \in\left[\ell_{k}(\mathrm{~F}(\mathrm{~B}))\right]^{\beta}$ for all $r \in \mathbb{N}$. Let the sequence $t$ be the $\mathrm{F}(\mathrm{B})$-transform of the sequence $s$, then we have

$$
\begin{aligned}
(\Phi t)_{r}= & \sum_{v=0}^{\infty} \phi_{r v} t_{v} \\
= & \sum_{v=0}^{\infty}\left(\sum_{j=v}^{\infty} x^{-1} \sum_{l=0}^{r-j}\left(\frac{-y+\sqrt{y^{2}-4 z x}}{2 x}\right)^{r-j-l}\left(\frac{-y-\sqrt{y^{2}-4 z x}}{2 x}\right)^{l} \frac{f_{j+1}^{2}}{f_{v} f_{v+1}} \psi_{r j}\right) \\
& \times\left(-z \frac{f_{v+1}}{f_{v}} s_{v-3}+\left(-y \frac{f_{v+1}}{f_{v}}+z \frac{f_{v}}{f_{v+1}}\right) s_{v-2}+\left(-x \frac{f_{v+1}}{f_{v}}+y \frac{f_{v}}{f_{v+1}}\right) s_{v-1}+x \frac{f_{v}}{f_{v+1}} s_{v}\right) \\
= & \sum_{v=0}^{\infty} \psi_{r v} s_{v} \\
= & (\Psi s)_{r}
\end{aligned}
$$

for all $v \in \mathbb{N}$. This gives $\Phi_{r} \in \ell_{1}$ for each $r \in \mathbb{N}$ and $\Phi t \in \mathrm{X}$. Thus we conclude that $\Phi \in$ $\left(\ell_{k}: \mathrm{X}\right)$.

Theorem 6.9 Let $1<k<\infty$. Then we have:

(a) If $\Psi \in\left(\ell_{k}(\mathrm{~F}(\mathrm{~B})): c_{0}\right)$, then $\left\|C_{\Psi}\right\|_{\chi}=\lim \sup _{r \rightarrow \infty}\left(\sum_{v=0}^{\infty}\left|\phi_{r v}\right|^{k^{\prime}}\right)^{1 / k^{\prime}}$.

(b) If $\Psi \in\left(\ell_{k}(\mathrm{~F}(\mathrm{~B})): c\right)$, then

$$
\frac{1}{2} \limsup _{r \rightarrow \infty}\left(\sum_{v=0}^{\infty}\left|\phi_{r v}-\phi_{\nu}\right|^{k^{\prime}}\right)^{1 / k^{\prime}} \leq\left\|C_{\Psi}\right\|_{\chi} \leq \limsup _{r \rightarrow \infty}\left(\sum_{\nu=0}^{\infty}\left|\phi_{r v}-\phi_{\nu}\right|^{k^{\prime}}\right)^{1 / k^{\prime}},
$$

where $\phi=\left(\phi_{v}\right)$ and $\phi_{v}=\lim _{r \rightarrow \infty} \phi_{r v}$ for each $v \in \mathbb{N}$.

(c) If $\Psi \in\left(\ell_{k}(\mathrm{~F}(\mathrm{~B})): \ell_{\infty}\right)$, then $0 \leq\left\|C_{\Psi}\right\|_{\chi} \leq \lim \sup _{r \rightarrow \infty}\left(\sum_{v=0}^{\infty}\left|\phi_{r v}\right|^{k^{\prime}}\right)^{1 / k^{\prime}}$.

(d) If $\Psi \in\left(\ell_{k}(\mathrm{~F}(\mathrm{~B})): \ell_{1}\right)$, then

$\lim _{m \rightarrow \infty}\|\Psi\|_{\left(\ell_{k}(\mathrm{~F}(\mathrm{~B})), \ell_{1}\right)}^{[m]} \leq\left\|C_{\Psi}\right\|_{\chi} \leq 4 \lim _{m \rightarrow \infty}\|\Psi\|_{\left(\ell_{k}(\mathrm{~F}(\mathrm{~B})), \ell_{1}\right)}^{[m]}$, where $\|\Psi\|_{\left(\ell_{k}\left(\mathrm{~F}(\mathrm{~B}), \ell_{1}\right)\right.}^{[m]}=\sup _{R \in \mathcal{R}_{m}}\left(\sum_{v=0}^{\infty}\left|\sum_{r \in R} \phi_{r v}\right|^{k^{\prime}}\right)^{1 / k^{\prime}}, m \in \mathbb{N}$.

(e) If $\Psi \in\left(\ell_{k}(\mathrm{~F}(\mathrm{~B})): c s_{0}\right)$, then $\left\|C_{\Psi}\right\|_{\chi}=\lim _{\sup _{r \rightarrow \infty}}\left(\sum_{v=0}^{\infty}\left|\sum_{m=0}^{r} \phi_{m v}\right|^{k^{\prime}}\right)^{1 / k^{\prime}}$.

(f) If $\Psi \in\left(\ell_{k}(\mathrm{~F}(\mathrm{~B})): c s\right)$, then

$$
\frac{1}{2} \limsup _{r \rightarrow \infty}\left(\sum_{v=0}^{\infty}\left|\sum_{m=0}^{r} \phi_{m v}-\tilde{\phi}_{\nu}\right|^{k^{\prime}}\right)^{1 / k^{\prime}} \leq\left\|C_{\Psi}\right\|_{\chi} \leq \limsup _{r \rightarrow \infty}\left(\sum_{v=0}^{\infty}\left|\sum_{m=0}^{r} \phi_{m v}-\tilde{\phi}_{\nu}\right|^{k^{\prime}}\right)^{1 / k^{\prime}},
$$

where $\tilde{\phi}=\left(\tilde{\phi}_{v}\right)$ with $\tilde{\phi}_{v}=\lim _{r \rightarrow \infty}\left(\sum_{m=0}^{r} \phi_{m v}\right)$ for each $v \in \mathbb{N}$.

(g) If $\Psi \in\left(\ell_{k}(\mathrm{~F}(\mathrm{~B})): b s\right)$, then $0 \leq\left\|C_{\Psi}\right\|_{\chi} \leq \lim \sup _{r \rightarrow \infty}\left(\sum_{v=0}^{\infty}\left|\sum_{m=0}^{r} \phi_{m v}\right|^{k^{\prime}}\right)^{1 / k^{\prime}}$.

\section{Proof}

(a) We observe by Lemma 6.1 that

$$
\left\|\Psi_{r}\right\|_{\ell_{k}(\mathrm{~F}(\mathrm{~B}))}^{*}=\left\|\Phi_{r}\right\|_{\ell_{k}}^{*}=\left\|\Phi_{r}\right\|_{\ell_{k^{\prime}}}=\left(\sum_{v=0}^{\infty}\left|\phi_{r v}\right|^{k^{\prime}}\right)^{1 / k^{\prime}}
$$


for $r \in \mathbb{N}$. Thus by applying Part (a) of Lemma 6.5, we immediately get the desired result.

(b) Observe that

$$
\left\|\Phi_{r}-\phi\right\|_{\ell_{k}}^{*}=\left\|\Phi_{r}-\phi\right\|_{\ell_{k^{\prime}}}=\left(\sum_{v=0}^{\infty}\left|\phi_{r v}-\phi_{v}\right|^{k^{\prime}}\right)^{1 / k^{\prime}}
$$

for each $r \in \mathbb{N}$. Now, let $\Psi \in\left(\ell_{k}(\mathrm{~F}(\mathrm{~B})): c\right)$, then using Lemma 6.1, we have $\Psi \in\left(\ell_{k}: c\right)$. Then applying Part (b) of Lemma 6.5, we get

$$
\frac{1}{2} \limsup _{r \rightarrow \infty}\left\|\Phi_{r}-\phi\right\|_{\ell_{k}}^{*} \leq\left\|C_{\Psi}\right\|_{\chi} \leq \limsup _{r \rightarrow \infty}\left\|\Phi_{r}-\phi\right\|_{\ell_{k}}^{*} .
$$

Thus, we realize that

$$
\frac{1}{2} \limsup _{r \rightarrow \infty}\left(\sum_{v=0}^{\infty}\left|\phi_{r v}-\phi_{\nu}\right|^{k^{\prime}}\right)^{1 / k^{\prime}} \leq\left\|C_{\Psi}\right\|_{\chi} \leq \limsup _{r \rightarrow \infty}\left(\sum_{\nu=0}^{\infty}\left|\phi_{r v}-\phi_{\nu}\right|^{k^{\prime}}\right)^{1 / k^{\prime}} .
$$

(c) The proof is analogous to the proof of Part (a) of Theorem 6.9 except that we employ Part (c) of Lemma 6.5 instead of Part (a) of Lemma 6.5.

(d) Clearly

$$
\left\|\sum_{r \in \mathbb{N}} \Phi_{r}\right\|_{\ell_{k}}^{*}=\left\|\sum_{r \in \mathbb{N}} \Phi_{r}\right\|_{\ell_{k^{\prime}}}=\left(\sum_{v=0}^{\infty}\left|\sum_{r \in \mathbb{N}} \phi_{r v}\right|^{k^{\prime}}\right)^{1 / k^{\prime}} .
$$

Let $\Psi \in\left(\ell_{k}(\mathrm{~F}(\mathrm{~B})): \ell_{1}\right)$, then $\Phi \in\left(\ell_{k}: \ell_{1}\right)$ by Lemma 6.8. Hence, using Lemma 6.6, we get

$$
\lim _{m \rightarrow \infty}\left(\sup _{R \in \mathcal{R}_{m}}\left\|\sum_{r \in R} \Phi_{r}\right\|_{\ell_{k}}^{*}\right) \leq\left\|C_{\Psi}\right\|_{\chi} \leq 4 \cdot \lim _{m \rightarrow \infty}\left(\sup _{R \in \mathcal{R}_{m}}\left\|\sum_{r \in R} \Phi_{r}\right\|_{\ell_{k}}^{*}\right) .
$$

This implies

$$
\lim _{m \rightarrow \infty}\left(\sup _{R \in \mathcal{R}_{m}}\left(\sum_{v=0}^{\infty}\left|\sum_{r \in R} \phi_{r v}\right|^{k^{\prime}}\right)^{1 / k^{\prime}}\right) \leq\left\|C_{\Psi}\right\| \leq 4 \cdot \lim _{m \rightarrow \infty}\left(\sup _{R \in \mathcal{R}_{m}}\left(\sum_{v=0}^{\infty}\left|\sum_{r \in R} \phi_{r v}\right|^{k^{\prime}}\right)^{1 / k^{\prime}}\right)
$$

as desired.

(e) It is clear that

$$
\left\|\sum_{m=0}^{r} \Psi_{m}\right\|_{\ell_{k}(\mathrm{~F}(\mathrm{~B}))}^{*}=\left\|\sum_{m=0}^{r} \Phi_{m}\right\|_{\ell_{k}}^{*}=\left\|\sum_{m=0}^{r} \Phi_{m}\right\|_{\ell_{k^{\prime}}}=\left(\sum_{v=0}^{\infty}\left|\sum_{m=0}^{r} \phi_{m v}\right|^{k^{\prime}}\right)^{1 / k^{\prime}} .
$$

Hence by using Part (a) of Lemma 6.7, we get the desired result.

(f) The proof is analogous to the proof of Part (e) of Theorem 6.9 except that we employ Part (b) of Lemma 6.7 instead of Part (a) of Lemma 6.7. 
(g) The proof is analogous to the proof of Part (e) of Theorem 6.9 except that we employ Part (c) of Lemma 6.7 instead of Part (a) of Lemma 6.7.

Corollary 6.10 Let $1<k<\infty$. Then the following results hold:

(a) Let $\Psi \in\left(\ell_{k}(\mathrm{~F}(\mathrm{~B})): c_{0}\right)$, then $\mathrm{C}_{\Psi}$ is compact if and only if $\lim _{r \rightarrow \infty}\left(\sum_{v=0}^{\infty}\left|\phi_{r v}\right|^{k^{\prime}}\right)^{1 / k^{\prime}}=0$.

(b) Let $\Psi \in\left(\ell_{k}(\mathrm{~F}(\mathrm{~B})): c\right)$, then $\mathrm{C}_{\Psi}$ is compact if and only if $\lim _{r \rightarrow \infty}\left(\sum_{v=0}^{\infty}\left|\phi_{r v}-\phi_{v}\right|^{k^{\prime}}\right)^{1 / k^{\prime}}=0$.

(c) Let $\Psi \in\left(\ell_{k}(\mathrm{~F}(\mathrm{~B})): \ell_{\infty}\right)$, then $\mathrm{C}_{\Psi}$ is compact if and only if $\lim _{r \rightarrow \infty}\left(\sum_{v=0}^{\infty}\left|\phi_{r v}\right|^{k^{\prime}}\right)^{1 / k^{\prime}}=0$.

(d) Let $\Psi \in\left(\ell_{k}(\mathrm{~F}(\mathrm{~B})): \ell_{\infty}\right)$, then $\mathrm{C}_{\Psi}$ is compact if and only if

$$
\lim _{m \rightarrow \infty}\left(\sup _{R \in \mathcal{R}_{m}}\left(\sum_{v=0}^{\infty}\left|\sum_{r \in R} \phi_{r v}\right|^{k^{\prime}}\right)^{1 / k^{\prime}}\right)=0 .
$$

(e) Let $\Psi \in\left(\ell_{k}(\mathrm{~F}(\mathrm{~B})): c s_{0}\right)$, then $\mathrm{C}_{\Psi}$ is compact if and only if

$$
\limsup _{r \rightarrow \infty}\left(\sum_{v=0}^{\infty}\left|\sum_{m=0}^{r} \phi_{m v}\right|^{k^{\prime}}\right)^{1 / k^{\prime}}=0
$$

(f) Let $\Psi \in\left(\ell_{k}(\mathrm{~F}(\mathrm{~B})): c s\right)$, then $\mathrm{C}_{\Psi}$ is compact if and only if

$$
\limsup _{r \rightarrow \infty}\left(\sum_{\nu=0}^{\infty}\left|\sum_{m=0}^{r} \phi_{m v}-\tilde{\phi}\right|^{k^{\prime}}\right)^{1 / k^{\prime}}=0
$$

(g) Let $\Psi \in\left(\ell_{k}(\mathrm{~F}(\mathrm{~B})):\right.$ bs), then $\mathrm{C}_{\Psi}$ is compact if and only if

$$
\limsup _{r \rightarrow \infty}\left(\sum_{\nu=0}^{\infty}\left|\sum_{m=0}^{r} \phi_{m v}\right|^{k^{\prime}}\right)^{1 / k^{\prime}}=0
$$

Theorem 6.11 The following results hold:

(a) If $\Psi \in\left(\ell_{\infty}(\mathrm{F}(\mathrm{B})): c_{0}\right)$, then $\left\|C_{\Psi}\right\|_{\chi}=\limsup _{r \rightarrow \infty} \sum_{v=0}^{\infty}\left|\phi_{r v}\right|$.

(b) If $\Psi \in\left(\ell_{\infty}(\mathrm{F}(\mathrm{B})): c\right)$, then

$$
\frac{1}{2} \limsup _{r \rightarrow \infty}\left(\sum_{v=0}^{\infty}\left|\phi_{r v}-\phi_{\nu}\right|\right) \leq\left\|C_{\Psi}\right\|_{\chi} \leq \limsup _{r \rightarrow \infty}\left(\sum_{v=0}^{\infty}\left|\phi_{r v}-\phi_{v}\right|\right),
$$

where $\phi=\left(\phi_{v}\right)$ and $\phi_{v}=\lim _{r \rightarrow \infty} \phi_{r v}$ for each $v \in \mathbb{N}$.

(c) If $\Psi \in\left(\ell_{\infty}(\mathrm{F}(\mathrm{B})): \ell_{\infty}\right)$, then $0 \leq\left\|C_{\Psi}\right\|_{\chi} \leq \limsup _{r \rightarrow \infty} \sum_{v=0}^{\infty}\left|\phi_{r v}\right|$.

(d) If $\Psi \in\left(\ell_{\infty}(\mathrm{F}(\mathrm{B})): \ell_{1}\right)$, then

$$
\lim _{m \rightarrow \infty}\|\Psi\|_{\left(\ell_{k}(\mathrm{~F}(\mathrm{~B})), \ell_{1}\right)}^{[m]} \leq\left\|C_{\Psi}\right\|_{\chi} \leq 4 \lim _{m \rightarrow \infty}\|\Psi\|_{\left(\ell_{k}(\mathrm{~F}(\mathrm{~B})), \ell_{1}\right)}^{[m]},
$$

where $\|\Psi\|_{\left(\ell_{k}(\mathrm{~F}(\mathrm{~B})): \ell_{1}\right)}^{[m]}=\sup _{R \in \mathcal{R}_{m}}\left(\sum_{v=0}^{\infty}\left|\sum_{r \in R} \phi_{r v}\right|\right), m \in \mathbb{N}$.

(e) If $\Psi \in\left(\ell_{\infty}(\mathrm{F}(\mathrm{B})): c s_{0}\right)$, then $\left\|C_{\Psi}\right\|_{\chi}=\limsup _{r \rightarrow \infty}\left(\sum_{v=0}^{\infty}\left|\sum_{m=0}^{r} \phi_{m v}\right|\right)$. 
(f) If $\Psi \in\left(\ell_{\infty}(\mathrm{F}(\mathrm{B})): c s\right)$, then

$$
\frac{1}{2} \limsup _{r \rightarrow \infty}\left(\sum_{v=0}^{\infty}\left|\sum_{m=0}^{r} \phi_{m v}-\tilde{\phi}_{\nu}\right|\right) \leq\left\|C_{\Psi}\right\|_{\chi} \leq \limsup _{r \rightarrow \infty}\left(\sum_{v=0}^{\infty}\left|\sum_{m=0}^{v} \phi_{m v}-\tilde{\phi}_{\nu}\right|\right),
$$

where $\tilde{\phi}=\left(\tilde{\phi}_{v}\right)$ with $\tilde{\phi}_{v}=\lim _{r \rightarrow \infty}\left(\sum_{m=0}^{r} \phi_{m v}\right)$ for each $v \in \mathbb{N}$.

(g) If $\Psi \in\left(\ell_{\infty}(\mathrm{F}(\mathrm{B})): b s\right)$, then $0 \leq\left\|C_{\Psi}\right\|_{\chi} \leq \lim \sup _{r \rightarrow \infty}\left(\sum_{v=0}^{\infty}\left|\sum_{m=0}^{r} \phi_{m v}\right|\right)$.

Proof The proof is analogous to the proof of Theorem 6.9.

Corollary 6.12 The following results hold:

(a) Let $\Psi \in\left(\ell_{\infty}(\mathrm{F}(\mathrm{B})): c_{0}\right)$, then $\mathrm{C}_{\Psi}$ is compact if and only if $\lim _{r \rightarrow \infty} \sum_{v=0}^{\infty}\left|\phi_{r v}\right|=0$.

(b) Let $\Psi \in\left(\ell_{\infty}(\mathrm{F}(\mathrm{B})): c\right)$, then $\mathrm{C}_{\Psi}$ is compact if and only if

$$
\lim _{r \rightarrow \infty}\left(\sum_{v=0}^{\infty}\left|\phi_{r v}-\phi_{\nu}\right|\right)=0
$$

(c) Let $\Psi \in\left(\ell_{\infty}(\mathrm{F}(\mathrm{B})): \ell_{\infty}\right)$, then $\mathrm{C}_{\Psi}$ is compact if and only if $\lim _{r \rightarrow \infty} \sum_{v=0}^{\infty}\left|\phi_{r v}\right|=0$.

(d) Let $\Psi \in\left(\ell_{\infty}(\mathrm{F}(\mathrm{B})): \ell_{1}\right)$, then $\mathrm{C}_{\Psi}$ is compact if and only if

$$
\lim _{m \rightarrow \infty}\left(\sup _{R \in \mathcal{R}_{m}}\left(\sum_{v=0}^{\infty}\left|\sum_{r \in R} \phi_{r v}\right|\right)\right)=0
$$

(e) Let $\Psi \in\left(\ell_{\infty}(\mathrm{F}(\mathrm{B})): c s_{0}\right)$, then $\mathrm{C}_{\Psi}$ is compact if and only if

$$
\limsup _{r \rightarrow \infty}\left(\sum_{v=0}^{\infty}\left|\sum_{m=0}^{r} \phi_{m v}\right|\right)=0
$$

(f) Let $\Psi \in\left(\ell_{\infty}(\mathrm{F}(\mathrm{B})):\right.$ ss), then $\mathrm{C}_{\Psi}$ is compact if and only if

$$
\limsup _{r \rightarrow \infty}\left(\sum_{v=0}^{\infty}\left|\sum_{m=0}^{r} \phi_{m v}-\tilde{\phi}\right|\right)=0 \text {. }
$$

(g) Let $\Psi \in\left(\ell_{\infty}(\mathrm{F}(\mathrm{B})):\right.$ bs), then $\mathrm{C}_{\Psi}$ is compact if and only if

$$
\limsup _{r \rightarrow \infty}\left(\sum_{v=0}^{\infty}\left|\sum_{m=0}^{r} \phi_{m v}\right|\right)=0
$$

Theorem 6.13 The following statements hold:

(a) If $\Psi \in\left(\ell_{1}(\mathrm{~F}(\mathrm{~B})): c_{0}\right)$, then $\left\|C_{\Psi}\right\|_{\chi}=\lim \sup _{r \rightarrow \infty}\left(\sup _{v \in \mathbb{N}}\left|\phi_{r v}\right|\right)$.

(b) If $\Psi \in\left(\ell_{1}(\mathrm{~F}(\mathrm{~B})): c\right)$, then

$$
\frac{1}{2} \limsup _{r \rightarrow \infty}\left(\sup _{v \in \mathbb{N}}\left|\phi_{r v}-\phi_{v}\right|\right) \leq\left\|C_{\Psi}\right\|_{\chi} \leq \limsup _{r \rightarrow \infty}\left(\sup _{v \in \mathbb{N}}\left|\phi_{r v}-\phi_{v}\right|\right),
$$

where $\phi=\left(\phi_{v}\right)$ and $\phi_{v}=\lim _{r \rightarrow \infty} \phi_{r v}$ for each $v \in \mathbb{N}$.

(c) If $\Psi \in\left(\ell_{1}(\mathrm{~F}(\mathrm{~B})): \ell_{\infty}\right)$, then $0 \leq\left\|C_{\Psi}\right\|_{\chi} \leq \lim \sup _{r \rightarrow \infty}\left(\sup _{v \in \mathbb{N}}\left|\phi_{r v}\right|\right)$. 
(d) If $\Psi \in\left(\ell_{1}(\mathrm{~F}(\mathrm{~B})): \ell_{1}\right)$, then $\left\|C_{\Psi}\right\|_{\chi}=\lim _{m \rightarrow \infty}\left(\sup _{v \in \mathbb{N}} \sum_{r=m}^{\infty}\left|\phi_{r v}\right|\right)$.

(e) if $\Psi \in\left(\ell_{1}(\mathrm{~F}(\mathrm{~B})): c s_{0}\right)$, then $\left\|\mathrm{C}_{\Psi}\right\|_{\chi}=\lim \sup _{r \rightarrow \infty}\left(\sup _{v \in \mathbb{N}}\left|\sum_{m=0}^{r} \phi_{m v}\right|\right)$.

(f) If $\Psi \in\left(\ell_{1}(\mathrm{~F}(\mathrm{~B})): c s\right)$, then

$$
\frac{1}{2} \limsup _{r \rightarrow \infty}\left(\sup _{v \in \mathbb{N}}\left|\sum_{m=0}^{r} \phi_{m v}-\tilde{\phi}_{v}\right|\right) \leq\left\|C_{\Psi}\right\|_{\chi} \leq \limsup _{r \rightarrow \infty}\left(\sup _{v \in \mathbb{N}}\left|\sum_{m=0}^{r} \phi_{m v}-\tilde{\phi}_{v}\right|\right),
$$

where $\tilde{\phi}=\left(\tilde{\phi}_{v}\right)$ with $\tilde{\phi}_{v}=\lim _{r \rightarrow \infty}\left(\sum_{m=0}^{r} \phi_{m v}\right)$ for each $v \in \mathbb{N}$.

(g) If $\Psi \in\left(\ell_{1}(\mathrm{~F}(\mathrm{~B})): b s\right)$, then $0 \leq\left\|C_{\Psi}\right\|_{\chi} \leq \lim \sup _{r \rightarrow \infty}\left(\sup _{v \in \mathbb{N}}\left|\sum_{m=0}^{r} \phi_{m v}\right|\right)$.

Proof The proof is analogous to the proof of Theorem 6.9.

\section{Corollary 6.14 The following results hold:}

(a) Let $\Psi \in\left(\ell_{1}(\mathrm{~F}(\mathrm{~B})): c_{0}\right)$, then $\mathrm{C}_{\Psi}$ is compact if and only if $\lim _{r \rightarrow \infty}\left(\sup _{v \in \mathbb{N}}\left|\phi_{r v}\right|\right)=0$.

(b) Let $\Psi \in\left(\ell_{1}(\mathrm{~F}(\mathrm{~B})): c\right)$, then $C_{\Psi}$ is compact if and only if $\lim _{r \rightarrow \infty}\left(\sup _{v \in \mathbb{N}}\left|\phi_{r v}-\phi_{v}\right|\right)=0$.

(c) Let $\Psi \in\left(\ell_{1}(\mathrm{~F}(\mathrm{~B})): \ell_{\infty}\right)$, then $\mathrm{C}_{\Psi}$ is compact if and only if $\lim _{r \rightarrow \infty}\left(\sup _{v \in \mathbb{N}}\left|\phi_{r v}\right|\right)=0$.

(d) Let $\Psi \in\left(\ell_{1}(\mathrm{~F}(\mathrm{~B})): \ell_{1}\right)$, then $\mathrm{C}_{\Psi}$ is compact if and only if $\lim _{m \rightarrow \infty}\left(\sup _{v \in \mathbb{N}} \sum_{r=m}^{\infty}\left|\phi_{r v}\right|\right)=0$.

(e) Let $\Psi \in\left(\ell_{1}(\mathrm{~F}(\mathrm{~B})): c s_{0}\right)$, then $\mathrm{C}_{\Psi}$ is compact if and only if

$$
\limsup _{r \rightarrow \infty}\left(\sup _{v \in \mathbb{N}}\left|\sum_{m=0}^{r} \phi_{m v}\right|\right)=0
$$

(f) Let $\Psi \in\left(\ell_{1}(\mathrm{~F}(\mathrm{~B})):\right.$ cs), then $\mathrm{C}_{\Psi}$ is compact if and only if

$$
\limsup _{r \rightarrow \infty}\left(\sup _{v \in \mathbb{N}}\left|\sum_{m=0}^{r} \phi_{m v}-\tilde{\phi}\right|\right)=0 .
$$

(g) Let $\Psi \in\left(\ell_{1}(\mathrm{~F}(\mathrm{~B})):\right.$ bs), then $\mathrm{C}_{\Psi}$ is compact if and only if

$$
\limsup _{r \rightarrow \infty}\left(\sup _{v \in \mathbb{N}}\left|\sum_{m=0}^{r} \phi_{m v}\right|\right)=0 .
$$

\section{Conclusion}

Recently, several authors constructed interesting Banach sequence spaces using the domain of special triangles, for instance İlkhan [26], İlkhan and Kara [24], Roopaei [54, 55], Roopaei et al. [53], and Yaying et al. [64]. We followed this approach and introduced $B K$ spaces $\ell_{k}(\mathrm{~F}(\mathrm{~B}))$ and $\ell_{\infty}(\mathrm{F}(\mathrm{B}))$ defined as the domain of the product matrix $\mathrm{F}(\mathrm{B}(x, y, z))$ in the spaces $\ell_{k}$ and $\ell_{\infty}$, respectively. The Fibonacci difference matrix $\mathrm{F}(\mathrm{B})$ is a generalized form of operators like $F\left(\Delta^{(2)}\right), F\left(\Delta^{(1)}\right)$ and $F$. Thus the results related to the matrix domain of the Fibonacci difference operator $F(B)$ are more general and comprehensive than the consequences on the matrix domain of operators $\mathrm{F}(\mathrm{B})(x, y), \mathrm{F}\left(\Delta^{(2)}\right), \mathrm{F}\left(\Delta^{(1)}\right)$ and $\mathrm{F}$. 


\section{Funding}

The authors extend their appreciation to the Deanship of Scientific Research at King Khalid University for funding this work through research groups program under Grant Number R.G.P.1/13/40.

Availability of data and materials

Not applicable.

\section{Competing interests}

The authors declare that they have no competing interests.

\section{Authors' contributions}

The authors contributed equally and significantly in writing this paper. The authors read and approved the final manuscript.

\section{Author details}

'Department of Mathematics, Dera Natung Government College, Itanagar 791113, India. ${ }^{2}$ Department of Mathematics, Gauhati University, Gauhati 781014, India. ${ }^{3}$ Department of General Required Courses, Mathematics, Faculty of Applied Studies, King Abdulaziz University, Jeddah 21589, Saudi Arabia. ${ }^{4}$ Operator Theory and Applications Research Group, Department of Mathematics, Faculty of Science, King Abdulaziz University, Jeddah 21589, Saudi Arabia. ${ }^{5}$ Department of Medical Research, China Medical University Hospital, China Medical University (Taiwan), Taichung, Taiwan. ${ }^{6}$ Department of Mathematics, Aligarh Muslim University, Aligarh 202 002, India. ${ }^{7}$ Department of Mathematics, College of Science, King Khalid University, Abha 61413, Saudi Arabia.

\section{Publisher's Note}

Springer Nature remains neutral with regard to jurisdictional claims in published maps and institutional affiliations.

Received: 25 September 2020 Accepted: 3 November 2020 Published online: 13 November 2020

\section{References}

1. Ahmad, Z.U., Mursaleen, M.: Köthe-Toeplitz duals of some new sequence spaces and their matrix maps. Publ. Inst. Math. (Belgr.) 42, 57-61 (1987)

2. Alotaibi, M., Mursaleen, M., Alamri, B., Mohiuddine, S.A.: Compact operators on some Fibonacci difference sequence spaces. J. Inequal. Appl. 2015, 203 (2015)

3. Alp, P.Z., Illkhan, M.: On the difference sequence space $\ell_{p}\left(\hat{T}^{9}\right)$. Math. Sci. Appl. E-Notes $7(2), 161-173$ (2019)

4. Altay, B., Başar, F., Mursaleen, M.: On the Euler sequence spaces which include the spaces $\ell_{p}$ and $\ell_{\infty}$ I. Inf. Sci. 176, 1450-1462 (2006)

5. Başar, F., Çakmak, A.F.: Domain of the triple band matrix on some Maddox's spaces. Ann. Funct. Anal. 3(1), 32-48 (2012)

6. Başar, F., Çolak, R.: Summability Theory and Its Applications. Bentham Science Publisher, İstanbul (2012)

7. Başarir, M., Başar, F., Kara, E.E.: On the spaces of Fibonacci difference absolutely $p$-summable, null and convergent sequences. Sarajevo J. Math. 12(2), 167-182 (2016)

8. Candan, M.: Domain of the double sequential band matrix in the classical sequence spaces. J. Inequal. Appl. 2012, $281(2012)$

9. Candan, M.: Almost convergence and double sequential band matrix. Acta Math. Sci. 34(2), 354-366 (2014)

10. Candan, M.: Domain of the double sequential band matrix in the spaces of convergent and null sequences. Adv. Differ. Equ. 2014, 163 (2014)

11. Candan, M.: A new approach on the spaces of generalized Fibonacci difference null and convergent sequences. Math. Æterna 5(1), 191-210 (2015)

12. Chaudary, B., Mishra, S.K.: A note on certain sequence spaces. J. Anal. 1, 139-148 (1993)

13. Das, A., Hazarika, B.: Some new Fibonacci difference spaces of non-absolute type and compact operators. Linear Multilinear Algebra 65(12), 2551-2573 (2017)

14. Das, A., Hazarika, B.: Matrix transformation of Fibonacci band matrix on generalized bv-space and its dual spaces. Bol. Soc. Parana. Mat. 36(3), 41-52 (2018)

15. Duyar, O., Demiriz, S., Ozdemir, O.: On some new generalized difference sequence spaces of non-absolute type. J. Math. 2014, 876813 (2014)

16. Ercan, S., Bektaş, Ç.: Some topological and geometric properties of a new BK-space derived by using regular matrix of Fibonacci numbers. Linear Multilinear Algebra 65(5), 909-921 (2017)

17. Esi, A., Hazarika, B., Esi, A.: New type of lacunary Orlicz difference sequence spaces generated by infinite matrices. Filomat 30(12), 3195-3208 (2016)

18. Et, M.: On some difference sequence spaces. Doğa-Turk. J. Math. 17, 18-24 (1993)

19. Furkan, H., Bilgiç, H., Başar, F.: On the fine spectrum of the operator $B(r, s, t)$ over the sequence spaces $\ell_{p}$ and $b v_{p}$. Comput. Math. Appl. 60(5), 2141-2152 (2010)

20. Gaur, A.K., Mursaleen, M.: Difference sequence spaces. Int. J. Math. Math. Sci. 21(4), 275-298 (1998)

21. Gnanaseelan, C., Srivastava, P.D.: The $\alpha-, \beta$-, $\gamma$-duals of some generalized difference sequence spaces. Indian J. Math. 38(2), 111-120 (1996)

22. IIlkhan, M.: Matrix domain of a regular matrix derived by Euler totient function in the spaces $c_{0}$ and $c$. Mediterr. J. Math. 17, $27(2020)$

23. Ilkhan, M.: A new conservative matrix derived by Catalan numbers and its matrix domain in the spaces $c$ and $c_{0}$. Linear Multilinear Algebra 68(2), 417-434 (2020)

24. Illkhan, M., Kara, E.E.: A new Banach space defined by Euler totient matrix operator. Oper. Matrices 13(2), 527-544 (2019) 
25. Illkhan, M., Kara, E.E., Usta, F.: Compact operators on the Jordan totient sequence spaces. Math. Methods Appl. Sci. (2020). https://doi.org/10.1002/mma.6537

26. IIlkhan, M., Şimşek, N., Kara, E.E.: A new regular infinite matrix defined by Jordan totient function and its matrix domain in $\ell_{p}$. Math. Methods Appl. Sci. (2020). https://doi.org/10.1002/mma.6501

27. Jarrah, A.M., Malkowsky, E.: Ordinary, absolute and strong summability and matrix transformations. Filomat 17, 59-78 (2003)

28. Kadak, U., Mohiuddine, S.A.: Generalized statistically almost convergence based on the difference operator which includes the ( $p, q)$-Gamma function and related approximation theorems. Results Math. 73(1), Article ID 9 (2018)

29. Kara, E.E.: Some topological and geometric properties of new Banach sequence spaces. J. Inequal. Appl. 2013, 38 (2013)

30. Kara, E.E., Başarir, M., Mursaleen, M.: Compactness of matrix operators on some sequence spaces derived by Fibonacci numbers. Kragujev. J. Math. 39(2), 217-230 (2015)

31. Kara, E.E., Demiriz, S.: Some new paranormed difference sequence spaces derived by Fibonacci numbers. Miskolc Math. Notes 16(2), 907-923 (2015)

32. Kara, E.E., Illkhan, M.: On some Banach sequence spaces derived by a new band matrix. Br. J. Math. Comput. Sci. 9, 141-159 (2015)

33. Kara, E.E., Illkhan, M.: Some properties of generalized Fibonacci sequence spaces. Linear Multilinear Algebra 64(11), 2208-2223 (2016)

34. Khan, V.A., Altaf, H., Abdullah, S.A.A., Esi, A., Al Shlool, K.M.A.S.: A study of Fibonacci difference ideal convergent sequences in random 2-normed space. Facta Univ. To appear

35. Kirişci, M., Başar, F.: Some new sequence spaces derived by the domain of generalized difference matrix. Comput. Math. Appl. 60(5), 1299-1309 (2010)

36. Kizmaz, H.: On certain sequence spaces. Can. Math. Bull. 24, 169-176 (1981)

37. Koshy, T.: Fibonacci and Lucus Numbers with Applications. Wiley, New York (2001)

38. Malkowsky, E:: A note on the Köthe-Toeplitz duals of generalized sets of bounded and convergent difference sequences. J. Anal. 4, 81-91 (1996)

39. Malkowsky, E., Mursaleen, Suantai, S.: The dual spaces of sets of difference sequences of order $m$ and matrix transformations. Acta Math. Sin. Engl. Ser. 23(3), 521-532 (2007)

40. Malkowsky, E., Rakočević, V:: An introduction into the theory of sequence spaces and measure of noncompactness. Zb. Rad. (Beogr.) 9(17), 143-234 (2000)

41. Malkowsky, E., Rakočević, V.: On matrix domains of triangles. Appl. Math. Comput. 189, 1146-1163 (2007)

42. Mohiuddine, S.A., Asiri, A., Hazarika, B.: Weighted statistical convergence through difference operator of sequences of fuzzy numbers with application to fuzzy approximation theorems. Int. J. Gen. Syst. 48(5), 492-506 (2019)

43. Mohiuddine, S.A., Hazarika, B.: Some classes of ideal convergent sequences and generalized difference matrix operator. Filomat 31(6), 1827-1834 (2017)

44. Mohiuddine, S.A., Raj, K.: Vector valued Orlicz-Lorentz sequence spaces and their operator ideals. J. Nonlinear Sci. Appl. 10, 338-353 (2017)

45. Mohiuddine, S.A., Raj, K., Mursaleen, M., Alotaibi, A.: Linear isomorphic spaces of fractional-order difference operators. Alex. Eng. J. (2020). https://doi.org/10.1016/j.aej.2020.10.039

46. Mursaleen, M.: Generalized spaces of difference sequences. J. Math. Anal. Appl. 203, 738-745 (1996)

47. Mursaleen, M., Başar, F:: Sequence Spaces: Topic in Modern Summability Theory. Group, Series: Mathematics and Its Applications. CRC Press, Boca Raton (2020)

48. Mursaleen, M., Başar, F., Altay, B.: On the Euler sequence spaces which include the spaces $\ell_{p}$ and $\ell_{\infty}$ II. Nonlinear Anal. 65(3), 707-717 (2006)

49. Mursaleen, M., Karakaya, V., Polat, H., Simsek, N.: Measure of noncompactness of matrix operators on some difference sequence spaces of weighted means. Comput. Math. Appl. 62, 814-820 (2011)

50. Mursaleen, M., Noman, A.K.: Compactness by the Hausdorff measure of noncompactness. Nonlinear Anal. 73, 2541-2557 (2010)

51. Mursaleen, M., Noman, A.K.: The Hausdorff measure of noncompactness of matrix operator on some BK spaces. Oper. Matrices 5(3), 473-486 (2011)

52. Mursaleen, M., Noman, A.K.: Compactness of matrix operators on some new difference sequence spaces. Linear Algebra Appl. 436(1), 41-52 (2012)

53. Roopaei, H., Foroutannia, D., Illkhan, M., Kara, E.E.: Cesàro spaces and norm of operators on these matrix domains. Mediterr. J. Math. 17, 121 (2020)

54. Roopei, H.: Norm of Hilbert operator on sequence spaces. J. Inequal. Appl. 2020, 117 (2020)

55. Roopei, H.: A study on Copson operator and its associated sequence space. J. Inequal. Appl. 2020, 120 (2020)

56. Sarigöl, M.A.: On difference sequence spaces. J. Karadeniz Tech. Univ. Fac. Arts Sci. Ser. Math. Phys. 10, 63-71 (1987)

57. Sönmez, A.: Some new sequence spaces derived by the domain of the triple band matrix. Comput. Math. Appl. 62, 641-650 (2011)

58. Sönmez, A.: Almost convergence and triple band matrix. Math. Comput. Model. 57, 2393-2402 (2013)

59. Sönmez, A., Başar, F:: Generalized difference spaces of non-absolute type of convergent and null sequences. Abstr. Appl. Anal. 2012, $435076(2012)$

60. Stieglitz, M., Tietz, H.: Matrixtransformationen von Folgenräumen eine Ergebnisübersicht. Math. Z. 154, 1-16 (1977)

61. Wilansky, A.: Summability Through Functional Analysis. North-Holland Mathematics Studies, vol. 85. Elsevier, Amsterdam (1984)

62. Yaying, T., Hazarika, B.: On sequence spaces generated by binomial difference operator of fractional order. Math. Slovaca 69(4), 901-918 (2019)

63. Yaying, T., Hazarika, B.: On sequence spaces defined by the domain of a regular Tribonacci matrix. Math. Slovaca 70(3), 697-706 (2020)

64. Yaying, T., Hazarika, B., Mursaleen, M.: On sequence space derived by the domain of $q$-Cesàro matrix in $\ell_{p}$ space and the associated operator ideal. J. Math. Anal. Appl. 493, 124453 (2021). https://doi.org/10.1016/j.jmaa.2020.124453 